\title{
"En un vergier..." Mélanges offerts à Marie-Françoise Notz, réunis et présentés par Joëlle Ducos et Guy Latry
}

\section{G. Matteo Roccati}

\section{(2) OpenEdition} Journals

Édition électronique

URL : https://journals.openedition.org/studifrancesi/2969

DOI : 10.4000/studifrancesi.2969

ISSN : 2421-5856

Éditeur

Rosenberg \& Sellier

Édition imprimée

Date de publication : 1 juillet 2013

Pagination : 425

ISSN : 0039-2944

\section{Référence électronique}

G. Matteo Roccati, " "En un vergier..." Mélanges offerts à Marie-Françoise Notz, réunis et présentés par Joëlle Ducos et Guy Latry », Studi Francesi [En ligne], 170 (LVII | II) | 2013, mis en ligne le 30 novembre 2015, consulté le 02 février 2023. URL : http://journals.openedition.org/studifrancesi/2969; DOI : https://doi.org/10.4000/studifrancesi.2969

Ce document a été généré automatiquement le 2 février 2023.

\section{c) (†) $\odot$}

Creative Commons - Attribution - Pas d'Utilisation Commerciale - Pas de Modification 4.0 International - CC BY-NC-ND 4.0

https://creativecommons.org/licenses/by-nc-nd/4.0/ 


\title{
"En un vergier..." Mélanges offerts à Marie-Françoise Notz, réunis et présentés par Joëlle Ducos et Guy Latry
}

\author{
G. Matteo Roccati
}

\section{RÉFÉRENCE}

"En un vergier..." Mélanges offerts à Marie-Françoise Notz, réunis et présentés par Joëlle Ducos et Guy LATRY, Pessac, Presses universitaires de Bordeaux, 2009 («Saber»), pp. 380.

Le recueil contient une trentaine de contributions qui portent sur des objets variés, à l'image de la curiosité intellectuelle de la dédicataire; les suivantes intéressent plus particulièrement la rassegna. Michèle GALLY, Délices ou épreuves? Le «beau verger» paradoxal, pp. 27-38 (sur Floire et Blanchefleur et les Echecs amoureux); Joëlle Ducos, Le nuage entre ciel et terre: le subtil et l'épais, pp. 57-66 (sur la description du nuage dans la météorologie médiévale); Jean-Marie SARPOULET, L'équidé philosophe, ou le cheval qui parlait à l'oreille de l'homme, pp. 117-123 (sur deux tensons de Bertran Carbonel); Lucienne DESCHAMPS, «Ma sorcière bien aimée» de l'Antiquité aux langues romanes: étude de certaines dénominations et représentations de la sorcière, pp. 127-134; Katy BERNARD, La voix de la dame dans la chanson d'aube occitane profane: de la lyrique à la narration, pp. 135-159; Hélène BASSO, L'espace d'un recueil amoureux, "La Louange des dames», pp. 177-196 (sur le recueil de Guillaume de Machaut); William D. PADEN, Alfred Jeanroy et la découverte française des troubadours, pp. 197-210; Pierre BEC, Note sur la lupinelle médiévale: "petite flûte» ou "cornemuse»?, pp. 211-220; Séverine ABIKER, Style chamarré. Remarques sur le traitement de la couleur dans "Li Mireoirs as dames" de Watriquet de Couvin, pp. 229-237; Danièle JAMES-RAOUL, La promotion de la métaphore dans les arts poétiques médiévaux des XII et XIII siècles, pp. 239-252; Nelly LABÈRE, La chute de la nouvelle d'oil, pp. 253-260; Nathalie 
GRANDE, Quelques réflexions sur la bibliothèque du «Nom de la Rose», pp. 279-286; Valérie FASSEUR, Des propriétés des choses selon Jean de Meun, pp. 287-298; Jean-René VALETTE, Métamorphoses et transsubstantiation: les «muances» du Graal, pp. 299-319; Patrice CAMBronne, Psychomachies... Entre littérature et plastique: Le Portail de Castelvieil (Gironde), essai de lecture, pp. 321-334 (sur l'origine littéraire du programme iconographique); Charles MAzOUER, La geste de David dans le théâtre religieux du Moyen Âge à la Renaissance, pp. 335-346; Catherine RAMOND, Réécritures, dramatisations: l'histoire du châtelain de Coucy et de la dame de Fayel au fil des siècles (XIII $\left.{ }^{e}-X V I I I^{e}\right)$, pp. 347-358. 